\title{
Resenhas
}

\section{Micro-história e tráfico transatlântico de escravos}

\section{D avid Eltis}

The D iligent: A Voyage Through the Worlds of theSlaveTrade, por Robert W. H arms. N oval orque: Basic Books, 2001, 448 pp.

A SlavingVoyageto Africa and Jamaica: TheL og of TheSandown, 1793-1794, por Bruce L. M ouser. Bloomington: IndianaU niversity Press, 2002, 224 pp.

Estes livros são apenas dois entre centenas de extensos relatos de primeira mão de viagens de navios negreiros. ${ }^{1}$ Suponho que cerca de 70 mil desses documentostenham sido escritos entre 1519 e1867, assumindo que cada uma das 37 mil viagens transatlânticas de negreiros possuía um diário de bordo e muitas igualmente tinham cadernos de cirurgiões etoda uma diversidade de outros tipos de relatos. Em suma, esses não são documentos raros. Eles abrangem desde registros mantidos como parte do negócio (diários de capitães e de cirurgiões, por exemplo), até memórias e relatos privados de viagens. Alguns fragmentos foram escritos ou pelo menos extraídos de depoimentos dos próprios africanos. M uitos derivam de oficiais de navios negreiros, ou de comerciantes e viajantes europeusque com eles estiveram em umaépoca em quechegar àÁfrica era atributo quase exclusivo dos navios negreiros. Entre estes últimos estava Zachary M acaulay, provavelmente o único abolicionista iluminista a fazer uma viagem transatlântica em um desses navios. $^{2}$

Para os interessados em construções a partir de registros históricos, tais documentos dividem-seem dois grupos: os que foram escritos antes edepois do comércio de escravos passar a ser visto como um mal em si mesmo. 0 primeiro grupo congrega o material maisinteressante, fornecendo pistas sobre atitudes 
acerca da escravidão radicalmente distintas das nossas. D iferentemente dos dias de hoje, a menos que encarada como alternativa à morte, ninguém jamais quis ser escravo. C ontudo, a grande mutação se deu quando as pessoas se convenceram deque ninguém deveria ser escravo, eos registros deexpedições negreiras surgidos depois disso constituem o segundo grupo. Eles são marcados por uma autoconsciência que está ausente dos escritos anteriores, e tendem a refletir uma imensa culpa ou a centrar a atenção sobre os horrores da middle passage para o novo público que então surgia. ${ }^{3}$

N os estertores do tráfico anglosaxão aparece um outro tipo dereação. 0 diário de bordo do negreiro L ouisa, de R hode Island, que navegou entre 1796 e 1797 - apenas três anos depois da única expedição do Sandown - descrevefielmentea viagem, mas procura evitar menções aos escravos, pois de acordo à lei de Rhodelsland a viagem erailegal. N 0 século XIX, traficantes e capitães de negreiros referiam-se aos seus cativos como "fardos" ao invés de escravos. No último diário de bordo conhecido, o do Wanderer, um negreiro que desembarcou na Geórgia em 1858, não apenas inexiste menção a escravos. N ão gratuitamente, depois delenão se registrou nenhum outro desembarque de africanos nos Estados Unidos.

$M$ as o que singulariza os casos apresentados por Robert $\mathrm{H}$ arms e Bruce M ouser?

Ambos são do período préabolicionista inglês, e esse éum bom caminho senospropusermosa entender o modo através do qual o tráfico de africanos era visto. Além disso, apesar do título do livro de M ouser, nenhum dos dois é um diário de bordo stricto sensu, apenas diários comuns. N esse sentido, o capitão do Sundow, Samuel Gamble, apresenta uma abordagem bastante real ista ao registrar aspectos vitais da viagem de seu negreiro - os números relativos à escravatura, por exemplo. Ele também levou consigo o diário quando temporariamente abandonou 0 negreiro na costa africana, emesmo na Jamaica, ocasião em que definitivamente rumou paraal nglaterraem outranau.

Pierre M ary era o capitão do D iligent, mas a descrição da viagem coube a Robert Durand, primeirotenentedo navio. Tanto seu registro quanto o do capitão Gamble apresentam detalhes muito mais minuciosos do que os que geralmente aparecem em documentos semeIhantes, e nesse caso a intervenção 
do narrador é intensa. Ademais, Durand nosnarra a primeiradesuas três viagens negreiras, e tudo o que via era-lhe novo, pelo que registrou detal hesqueobservadoresmais experientespodiam ignorar. A densidade com que narra cada detalhe singulariza o relato de $D$ urand frente ao deGambleedeoutros. Por contraste, Samuel G ambleesteve no litoral africano pelo menos duas vezes antes desseescrito (uma como capitão, apesar deM ouser não o mencionar). Sobretudo, entretanto, ambos trazem ilustrações preciosas, o que os faz destacarem-se dentreas centenas outros relatos sem importância nos arquivosemuitas vezesjáimpressos.

Como podem os acadêmicosse utilizar do relato de uma simples viagem (ou, como também foi recentementefeito, deum único africano transportado atravésdo A tlântico) ${ }^{4}$ para trazer à luz a complexidade da travessia de mais ou menos 37 mil negreiros, que carregaram milhões de africanos e seus captores? Três grandes abordagens mevêm à mente. U ma éa publicação do texto $\mathrm{em}$ seu formato original, acompanhada de copiosas notas sobre todos os termos estranhos a nós, junto com informações básicas acerca dos lugares eeventos mencionados. O utra é trazer estas informações básicas para o primeiro plano, visando de monstrar o quão típica era a viagem frenteàs demais expediçõesnegreiras. Ambos, obviamente, são procedimentos necessários eúteis.

U materceira - talvez a abordagem mais refinada -, em adição à primeira ou à segunda, seria tentar examinar a viagem da perspectiva que questiona como foi possível a um grupo de seres humanos subjugar outro a condições tão horríveis quanto as presentes em cada expedição negreira. D ito deoutro modo: dever-se-ia explicar como épossível queval ores culturais possam mudar tanto e tão rapidamente. Isso seria, sem dúvida, uma contribuição não apenas ao tema específico em questão, mas ao estudo da humanidade em geral. A análisedossistemasescravistasdas Américase do tráfico queos alimentou nuncaestevetão necessitada de semelhante perspectiva.

A primeira abordagem foi a triIhada por Bruce M ouser na edição do relato da viagem do Sandown, em 1793-94. 0 capitão G amble já está a bordo logo na primeira página do livro, eregressaàl nglaterra nas páginasfinais. Várias passagens do meio do livro contêm tão somente duas linhas do texto original, e mais de trinta constituídas apenas por notas e comentários. M ouser não deixa 
nenhum termo ou aspecto sem explicação, exceto, estranhamente, no que se refere à mai or parte dos outros navios negreiros mencionados - em que pese a existência de vários catálogos já publicados que tornam fácil tal identificação. A voz de G amble está em toda parte. M ouser parece ter lido tudo sobre a região da Serra Leoa ondeo Sandown foi comprar cativos, ese utiliza plenamente dos conhecimentos acumulados ao longo desua carreira acadêmica. Ele escolheu imprimir o texto original exatamente como foi escrito, completo, com seus traços e marcas. Apesar disso, aspectos recônditos da viagem permanecem inexplicados, e há mais a ser dito sobre a proveniência desse navio do que M ouser nos oferece. $\mathrm{H}$ á também algumas repetições nas notas, mas o trabalho ésem dúvida cuidadoso einteligente.

0 livro de Robert $\mathrm{H}$ arms encarna a segunda abordagem eémarcado por grandes pretensões. Ele converte 113 páginas de manuscrito em 450 impressas, em boa parte por meio da amplificação dos originais de D urand através de material descritivo eanedótico. 0 D iligent é mencionado nas duas primeiras páginas, e novamente nas páginas 31 e 32, mas a embarcação sequer começa a ser equipada atéa página 65 , eainda está no porto na 85. Ao contrário, nesse ponto o livro deM ouser, a despeito das extensas notas de rodapé, se encontra próximo do fim de uma prolongada estadia na costa africana. O sprimeirosseiscapítulos de H arms cobrem a controvérsia sobre o estatuto de um escravo na França metropolitana, o conflito entre os J ansenistas e os J esuítas, a política comercial francesa, e o escândalo de John Law, sendo boa parte disso tudo repleto de detal hes cotidianos, tais como o tamanho dos atoleiros de uma estrada para um convento de $\mathrm{N}$ antes, em janeiro de 1714 - aspecto provavelmente constante de registros históricos mas, mesmo assim, pouco apropriado em termos denarrativa. Eiso tom do restantedo livro. $H$ álongasdigressões sobre o caso Bulfinche Lambe, envolvendo um agenteinglêstransformado em escravo excepcionalmentebem tratado pelo rei deAjudá em meados da década de 1720, 0 terremoto na M artinica em 1727, e diversos dados acerca de um período que se estende até uma geração antes do D iligent partir deVannestudo apresentado detal hadamentee em estilo muito próximo ao de um romancista.

O sestudantes certamenteacharão o trabalho de H arms mais inte- 
ressante. Por seu turno, osacadêmicosprovavelmenteencontrarão mais razões para consultar o volume de M ouser. Ambos são fortes em África e fracos em Américas, e em tudo são mais bem sucedidos do que 0 relato de $\mathrm{N}$ igel Tattersfield sobre a viagem do Danie - a mais recente publicação paralela a eles- , quetenta combinar as duas abordagens mencionadas. ${ }^{5}$ Como Tattersfield, nenhum dos dois busca enfronharse na literatura corrente sobre o tráfico de escravos, a não ser por referênciasocasionais- o caso deH arms. 0 que esse dois volumes cuidadosamente pesquisados e bem escritos oferecem é muita informação básica, uma narrativa vívida, e, no caso de M ouser, a inestimável oportunidade de entrar em contato com anotações cotidianas de um indivíduo comprometido com o que é hoje classificado como um anátema. $A$ busca de M ouser em elucidar o texto original recupera, de modo apropriado, o espírito descomprometido com que foi redigido o manuscrito original.

Ao final, entretanto, a descrição da viagem do D iligent pode ser um exemplo dos limites da microhistória enquanto gênero. Localizada normalmente em algum ponto entreabiografiaea narrativa, a micro- história permitirá ao leitor imergir numa cotidianidademuito distintada nossa. 0 efeito, no entanto, não necessariamente alargará nosso entendimento histórico, mas, paradoxalmente, pode aumentar a distância entre os eventos e o leitor. Em um sentido muito específico, semelhante tratamento pode confirmar o sujeito histórico como o "outro" para, finalmente, afirmar a própria interpretação do leitor acerca dosvalores e das diferenças culturais. Tal tendência é acentuada quando $\mathrm{H}$ arms freqüentemente nos lembra de que os val ores da França do século XV III eram diferentes dos de hoje. 0 sofrimento dos escravos ou a má conduta dos comerciantes de cativos irá somentenoslevar a entender osmotivospelosquaiso tráfico transatlântico de escravos pôde existir. A exemplo das tensões entre as culturas, discernimento e compreensão começam apenas quando o leitor é encorajado a reconhecer uma humanidade partilhada pelos agentes históricos através dos séculos.

Para a análise da mudança histórica, quanto pode ser esperado de uma simples viagem?Tomemosapenas um exemplo da face africana presente no livro. D urand chegou em Jaquim um ano antes desta ser invadida pelo $\mathrm{D}$ aomé, talvez a mais 
poderosa detodas as potências escravistas africanas. Q uatro anos antes, D aométinha conquistado Ajudá, o porto maisimportante deembarque de escravos da África O cidental. Como resultado, Ajudá constantemente perdeu espaço para outros centros de embarque de escravos na Baía deBenim - primeiro para Popó, depoispara Porto $\mathrm{N}$ ovo e, finalmente, para Lagos. I solada de todas as grandes regiões escravistas da costa africana, a Baía deBenim chegou ao pico desuas exportações de escravos para as Américas no primeiro quarto do Setecentos - exatamente quando Ajudá ainda era independente e concentrava mais de $80 \%$ de todas as partidas da região. Logo, a viagem do D iligent coincidiu com uma enorme alteração na proveniência dos cativosno âmbito da C osta dosEscravos, movimento caudatário do quão independentementeAjudáeo D aomé imperial organizavam a captura e a venda de escravos. 0 texto apresenta apenas al gumas dicas acerca dessasalterações profundas, equasenenhuma importância dá aos detalhes sobre a interação entre africanos e europeus, subjacentes à transação por cativos. Poderia fazer muito mais. Se isso ocorre para a face africana, à qual se dedica quase metade do livro, a lacuna é ainda mais grave quando se pensa nos fatores culturais e econômicos mais amplos, aos quais devemos nos remeter para apenas começar a entender a escravidão eo tráfico de escravos no M undo Atlântico.

tradução de D aniel B. D omingues da Silva

\section{Notas}

${ }^{1}$ O sdiários de bordo de quase todas as 143 viagensnegreiras da Companhia de Comércio de M iddleburgsche chegaram até nós, assim como talvez oitenta dos diários de bordo dos navios pertencentes a companhias que operavam fora de Lorient. Pelo menos muitos outros estão para ser achadosnosarquivos deN antes. 0 Public Record O ffice em Londres possui muitos nas séries T 70 e Chancery. N os Estados U nidos, exemplos do gênero estão para ser encontrados na maioria das bibliotecas- paranão falar dosarquivos delíngua portuguesa pelo Atlântico.

${ }^{2} \mathrm{C}$ f. o notável relato do cirurgião do Saint $M$ ichel durantea sua estadia em M adagascar em 1726 nos arquivos da $\mathrm{H}$ ispanic Society of America ("Journal and Logbook of an Anonymous Scotch Sailor held on his voyagefrom London to Jamaica, and from London to Madagascar and Buenos Ayres... "); Awnsham Churchill e John Churchill, A Collection of Voyages and Travels... (Londres, 1744-6), vol. 6; $\mathrm{Nem}$ todos são de oficiais. Veja o diário mantido por um adolescente do interior que navegou no Thomas de Liverpool para Barbados - o diário deM ackenzieno N ew York Public Library. 0 único fragmento restante da 
parte relevante do diário de $M$ acaulay, infelizmente, são aquel es impressos na biografia da Viscondessa Knutsford - Life and Lettersof ZackaryM acaulay (Londres, 1900), pp. 45-46.

${ }^{3}$ Veja os vários relatos eilustrações que preenchem a literatura depanfleto abolicionista e as revistas emergentes do século XIX para ilustrações confira o site da Virginia Foundation of the Humanities http:// gropius.lib.virginia.edu/Slavery/. Vejatambém os relatos sobre o tráfico de escravos contidosem Robert Edgar Conrad, Children of God's Fire a D ocumentary H istory of B lack Slaveryin Brazil (Princeton, 1986), pp. 23-53.

${ }^{4}$ Robin Law e Paul E. Lovejoy (eds.), The Biography of M ahommah Gardo Baquaqua: hisPassagefrom Slavery to Freedom in Africa and America (Princeton, 2001).

${ }^{5}$ T he Forgotten Trade: Comprising the Log of theD anie and $H$ enry of 1700 and Accounts of the Slave Trade from the M inor Ports of England, 1698-1725 (Londres, 1991). 